\title{
CHEMICAL EXPLORATORY ANALYSIS OF PRINTED CIRCUIT BOARD (PCB) USING INDUCTIVELY COUPLED PLASMA OPTICAL EMISSION SPECTROMETRY (ICP OES): DATA TREATMENT AND ELEMENTS CORRELATION
}

\author{
Jeyne Pricylla Castro and Edenir Rodrigues Pereira-Filho *
}

Group of Applied Instrumental Analysis, Chemistry Department, Federal University of São Carlos, São Carlos, São Paulo State, Brazil

Article Info:
Received:
27 April 2020
Revised:
27 July 2020
Accepted:
24 August 2020
Available online:
28 December 2020
Keywords:
Urban mining
PCB element distribution maps
Scores map
Electronic waste
Correlation plot

\section{INTRODUCTION}

Nowadays, around 60 different chemicals elements are found in electrical and electronic equipment (EEE), making this type of material a powerful economic and technological source. While the lifespan of these equipment is decreasing over the years due to the fast-technological development, the amount of electronic waste (e-waste) increases (Baldé et al., 2017; Andrade et al., 2019a; Costa et al., 2018).

The composition of e-waste contains precious metals, valuable bulky materials, rare earth elements (REE), hazardous and scarce metals, being extremely important to recycle these obsolete materials. Initiatives related to recycling avoid health and environmental risks, minimizing impacts caused by primary metal extraction, being also a strategic commercial sector (Zhang et al., 2017; Bookhagen et al., 2018). Therefore, the e-waste should be considered a source of valuable resources, and not a common waste (Cucchiella et al., 2015).

Printed circuit board (PCB) is one type of e-waste, which is found in almost all EEE. It consists of a board composed of layers of polymers and fibrous materials, such as, glass fiber. Conductive lines are printed and, electronic components (transistors, capacitors, integrated circuits) are mounted on the board (Yamane et al., 2011; Cayumil et al., 2018). There are many elements on the PCB, increasing its complexity and heterogeneity, even so, the interest to recycle this type of material increase over the years (Yamane et al., 2011; Cayumil et al., 2018).

It is necessary several steps to recycle this material: pre-treatment (manual disassembling); processing (comminution, granulometric classification, magnetic and electrostatic separation); concentration (pyro and hydrometallurgical processing); recovery and purification (solvent extraction, precipitation/cementation) (Silvas et al., 2015). In the literature, there are some studies that show several recycling routes (Cui \& Zhang, 2008; Huang et al., 2009; Park \& Fray, 2009; Rao et al., 2020).

In the study proposed by Dervisevic et at., 2013, the quantitative analysis of the PCBs (individual components and complete $\mathrm{PCB}$ ) from computer and mobile phones 
were performed using inductively coupled plasma optical emission spectrometry (ICP OES) and $x$-ray fluorescence (XRF). Besides that, structure and chemical composition, phase transformations and microstructural analysis were performed. In addition, a recycling procedure was proposed observing the effect of the extraction in different parts of PCB before the melting process. The authors suggested also new materials that can replace the harmful ones, as an example, Ga-Sb-Zn as a good lead-free solder material.

Tanvar et al., 2020, evaluate hard disk drive (HDD) as a source of $\mathrm{Cu}$ and REE and, performed physical separation in a customized water fluidization classifier for Cu recovery from PCB. The extraction of REE elements from the magnet were performed using microwave exposure-leaching and precipitation route. Another study was performed by Moosakazemi et al., 2020, where the authors proposed a cementation process using waste Al-based heat sinks as cementing agent to precipitate $\mathrm{Sn}$ and $\mathrm{Pb}$ from the dissolution of PCBs in $\mathrm{HCl}$. El-Nasr et al., 2020, used a leach solution (ammonia salt leaching process) for PCB from old computers to prepare Cu nanoparticle using an ecofriendly and low-cost method with L-ascorbic acid as reductant and stabilizer. Mesquita et al., 2018, described a chemical characterization of connector pins from PCB of computers using Scanning Electron Microscopy - Energy Dispersive Spectroscopy (SEM-EDS) and ICP OES. The authors concluded that, due to leaching procedure of the mixed sample without grinding, the operating costs were reduced and metals recovery were maximized.

Andrade et al., 2019b, prepared a reference material for inorganic constituents on PCB samples. They evaluated different acid mixtures for leaching procedure. Diluted aqua regia presented the best performance using microwave radiation and ICP OES for determination of several elements. Instrumental neutron activation analysis (INAA) was used to compare the results obtained. After that, several characterizations were performed according to ISO Guides 30-35, such as homogeneity, stability (short and long) and chemical characterization of the reference material (Andrade et al., 2019c).

An important aspect in all studies is the characterization of the material and, one of the most used instrumental analytical techniques is ICP OES (Castro \& Pereira-Filho, 2018). This technique is already well established, with many advantages such as multielement determination, accurate and precise determinations and, low limits of detection (LODs), being necessary dissolution of the solid samples. In this study, ICP OES was used to analyze a PCB from HDD. The goal was dedicated to exploratory analysis using correlation plot, PCB element distribution maps and, scores maps and loading plot using the concentrations acquired from ICP OES. The images help to interpret and correlate the different elements on the PCB, characterizing this material and collaborating with urban mining.

\section{MATERIAL AND METHODS}

\subsection{Sample preparation, digestion procedure and ICP OES analysis}

A PCB from HDD was chosen to perform this study. This PCB was mechanically fragmented in 77 squareshaped sub-samples (11 rows and 7 columns) with the help of a lathe. The size of each fragment was around 1 by $1 \mathrm{~cm}$. To avoid intense sample preparation procedures, the fragments were not crushed and milled, but entirely used. Therefore, it was not possible to obtain replicates due to heterogeneity of the sample. Even for a single manufacturer, PCB's are not exactly the same in composition.

The fragments' weight ranged from 0.41 to $1.63 \mathrm{~g}$, and were separated according to their weights to further mineralization, which was performed using a microwave system (Speedwave four, Berghof, Eningen, BW, Germany). Seven $\mathrm{mL}$ of concentrated aqua regia $\left(\mathrm{HNO}_{3}\right.$ and $\mathrm{HCl}$ in a $1: 3$ ratio) was used as acid mixture. The acids used were previously purified in a sub-boiling distillation system. Table 1 shows the heating program used in the microwave for DAK 100 tube, that allows up to $100 \mathrm{~mL}$ of volume.

After the mineralization, the final solutions volume was completed until $20 \mathrm{~mL}$ with deionized water (Milli-Q ${ }^{\circledR}$, Millipore, Bedford, MA, USA). Consecutive dilutions were performed to ensure that the solutions would be fit for maximum allowed for dissolved solids and acidity. ICP OES (Thermo Scientific, iCAP 7000) was used to determine Al, $\mathrm{Au}, \mathrm{Ba}, \mathrm{Ca}, \mathrm{Co}, \mathrm{Cr}, \mathrm{Cu}, \mathrm{Fe}, \mathrm{Mg}, \mathrm{Mn}, \mathrm{Nd}, \mathrm{Ni}, \mathrm{Pb}, \mathrm{Pd}, \mathrm{Pt}, \mathrm{Sb}$, $\mathrm{Sn}, \mathrm{Ti}$ and $\mathrm{Zn}$. The determinations were performed in axial mode, except for $\mathrm{Ba}$ and $\mathrm{Ca}$, that were determined in radial mode, due to high concentration of these elements on the sub-samples. Table 2 shows the ICP OES instrumental parameters.

For Ag, Flame Atomic Absorption Spectrometry (FAAS) was used. The FAAS instrument (Varian AA240FS, Mulgrave, Australia) performed the determinations with a hollow cathode lamp of $\mathrm{Ag}$. The spectrometer parameters used were wavelength of $328.1 \mathrm{~nm}$, lamp current of $3 \mathrm{~mA}$ ( $75 \%$ of the manufacturer's recommendation), spectral resolution of $0.5 \mathrm{~nm}$ in absorbance measurement mode. The flame type was Air- $\mathrm{C}_{2} \mathrm{H}_{2}$ with a flow of $1.3 \mathrm{~L} \mathrm{~min}$.

Limits of detection and quantification were calculated

TABLE 1: Microwave heating program used for fragments' mineralization.

\begin{tabular}{|c|c|c|c|c|}
\hline Steps & Temperature $\left({ }^{\circ} \mathrm{C}\right)$ & Ramp time (min) & Hold time (min) & $\begin{array}{l}\text { Percentage of maximum } \\
\text { pressure }{ }^{\star} \text { used }(\%)\end{array}$ \\
\hline 1 & 120 & 5 & 5 & 60 \\
\hline 2 & 150 & 5 & 2 & 70 \\
\hline 3 & 200 & 5 & 15 & 80 \\
\hline
\end{tabular}

* The maximum pressure is 30 bar 
TABLE 2: Instrumental parameters for ICP OES determinations.

\begin{tabular}{|c|c|}
\hline Instrumental Parameters & Operation conditions \\
\hline Power applied by RF (W) & 1150 \\
\hline Nebulizer gas flow rate (L/min) & 0.70 \\
\hline Auxiliary gas flow rate (L/min) & 0.5 \\
\hline Argon gas flow rate (L/min) & 12 \\
\hline Integration time / s & 15 for low and 5 for high emission lines \\
\hline Analytes & Emission Lines (nm) \\
\hline Al & I 308.215 \\
\hline $\mathrm{Au}$ & I 267.595 \\
\hline $\mathrm{Ba}$ & II 493.41 \\
\hline $\mathrm{Ca}$ & 422.673 \\
\hline Co & II 228.616 \\
\hline $\mathrm{Cr}$ & II 284.325 \\
\hline $\mathrm{Cu}$ & 1327.396 \\
\hline $\mathrm{Fe}$ & II 239.562 \\
\hline $\mathrm{Mg}$ & II 280.27 \\
\hline $\mathrm{Mn}$ & II 260.569 \\
\hline $\mathrm{Nd}$ & II 401.225 \\
\hline $\mathrm{Ni}$ & II 231.604 \\
\hline $\mathrm{Pb}$ & II 220.353 \\
\hline$P d$ & 1340.458 \\
\hline $\mathrm{Pt}$ & II 203.646 \\
\hline $\mathrm{Sb}$ & 217.581 \\
\hline Sn & 1283.999 \\
\hline $\mathrm{Ti}$ & II 338.376 \\
\hline $\mathrm{Zn}$ & 213.856 \\
\hline
\end{tabular}

according to Equation 1 and 2:

$L O D=\frac{3 \times s d_{\text {blank }}}{\text { sensitivity }}$

$L O Q=\frac{10 \times s d_{\text {blank }}}{\text { sensitivity }}$

Where $s d_{\text {blank }}$ is the standard deviation of blank solutions signals.

\subsection{Exploratory analysis}

With the concentrations obtained by ICP OES determination, PCB element distribution maps, scores maps and loading plot, besides correlation plots were performed in order to visualize and interpret the data. For the scores and loading, the data were auto-scaled and the images were constructed according to the results from Principal Component Analysis (PCA). For correlation plot, the values were calculated with Pearson correlation. More details about these plots are written in the section "Results and Discussion". All data organization, treatment, calculation, and figures preparation were made in MATLAB 2017b (Matworks, Natick, MA, USA.

\section{RESULTS AND DISCUSSION}

\subsection{Concentration values acquired by ICP OES}

A PCB from HDD was studied and, in this case, the goal was to verify the distribution of the elements on the board without milling process. The main advantages are minimum sample preparation and maximum recovery of the elements, since each small fragment is analyzed individually. On the other hand, for some fragments the resulting mineralized solution was not entirely free of solid residues. These samples contain a lot of polymers and silicon.

Table 3 presents the concentration values obtained by ICP OES for $\mathrm{Al}, \mathrm{Au}, \mathrm{Ba}, \mathrm{Ca}, \mathrm{Co}, \mathrm{Cr}, \mathrm{Fe}, \mathrm{Mg}, \mathrm{Mn}, \mathrm{Nd}, \mathrm{Ni}, \mathrm{Pb}, \mathrm{Pd}$, $\mathrm{Pt}, \mathrm{Sn}, \mathrm{Ti}$ and $\mathrm{Zn}$. For $\mathrm{Ag}$, the results were obtained using FAAS. LOD and LOQ are also showed in Table 3. The PCB was split in 77 sub-samples, which were named according to the position of them on the board. For example, row 1 and column 1 is the first sub-sample. There are 11 rows and 7 columns. The concentration values are in a range from the minimum to maximum of each row among the 7 columns. In the case of $\mathrm{Ag}$, concentration obtained in the row 1 (R: 1) and the 7 columns (C: 1 to 7 ) ranged from 201 to $415 \mathrm{mg} \mathrm{kg}^{-1}$ (see Table 3 ).

The most abundant element on the PCB is $\mathrm{Cu}$ with maximum concentration around $30 \% \mathrm{~m} \mathrm{~m}^{-1}$ in row 11 and column 3 (see Table 3, concentration value of $299482 \mathrm{mg}$ $\left.\mathrm{kg}^{-1}\right)$, followed by Fe $\left(\sim 11 \% \mathrm{~m} \mathrm{~m}^{-1}\right.$, row 7 , column 3$)$, Sn ( $8 \% \mathrm{~m} \mathrm{~m}^{-1}$, row 11 , column 3$)$, Ca $\left(\sim 7 \% \mathrm{~m} \mathrm{~m}^{-1}\right.$, row 8 , column 6$)$ and $\mathrm{Pb}\left(\sim 4 \% \mathrm{~m} \mathrm{~m}^{-1}\right.$, row 11 , column 2$)$. Among the precious or noble metals, $\mathrm{Pd}$ is the most abundant on the PCB with $0.31 \% \mathrm{~m} \mathrm{~m}^{-1}$ in row 3 and column 2, followed by $\mathrm{Au}\left(0.15 \% \mathrm{~m} \mathrm{~m}^{-1}\right.$, row 10 , column 3$), \mathrm{Pt}\left(0.11 \% \mathrm{~m} \mathrm{~m}^{-1}\right.$, row 7 , column 3$)$ and $\mathrm{Ag}\left(0.07 \% \mathrm{~m} \mathrm{~m}^{-1}\right.$, row 9 , column 6$)$.

Harmful elements, as $\mathrm{Cr}$ and $\mathrm{Pb}$, were determined on the PCB with low concentration for $\mathrm{Cr}$ (maximum of 43 $\mathrm{mg} \mathrm{kg}^{-1}$ ). On the other hand, high concentrations for $\mathrm{Pb}$ were determined (from 0.16 to $4 \% \mathrm{~m} \mathrm{~m}^{-1}$ ), which is present on the solder material. Neodymium, a REE, was also determined with high concentrations for some fragments $\left(0.90 \% \mathrm{~m} \mathrm{~m}^{-1}\right.$ for row 3 and column 4$)$. Therefore, it can be observed huge variability of different elements that are present on a PCB from HDD.

\subsection{Exploratory analysis using different tools}

As described in the last section and Table 3 , the results obtained for a single PCB are chemically rich, but how these elements are correlated? Is it possible to identify a group of elements that can be recycled together? These questions will be clarified in this section. For better visualization of the data, several images were built. The scores map and loading plot are based on PCA, as mentioned before, that describe the original dataset, simplifying and reducing the number of variables without losing information (Sperança et al., 2017; Carvalho et al., 2015; Santos et al., 2018). The data were organized in a matrix with 77 samples (sub-samples) and 21 variables (elements concentration) and, this dataset was auto-scaled to give the same importance to all variables. The dataset is represented in a new space with principal components (PC's). In this case, 21 variables or dimensions (elements concentration) were reduced to 2 new variables with $20 \%$ and $18 \%$ of explained variance for PC1 and PC2, respectively. Figure 1 shows the original PCB before the lathe process (split in 77 sub-samples with 11 rows and 7 columns), the scores and loadings for PC1 


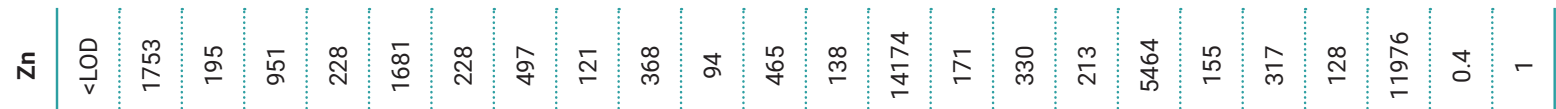

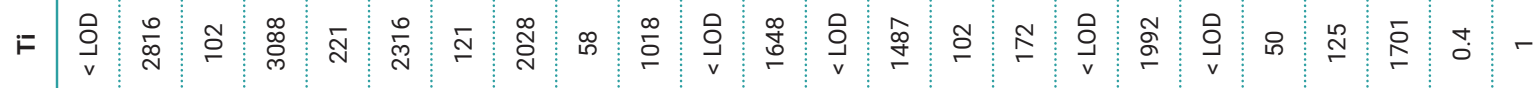

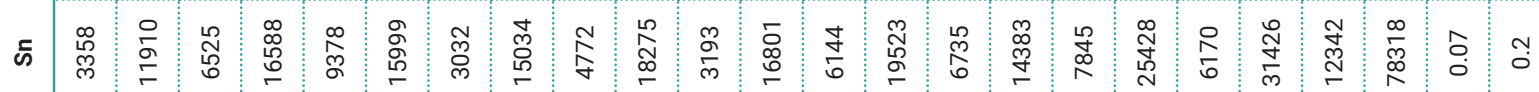
의

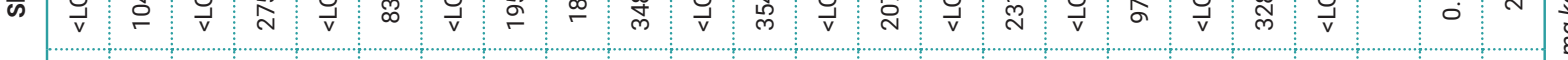

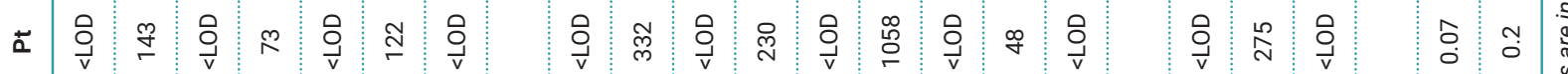

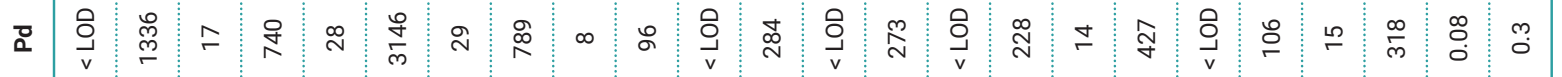

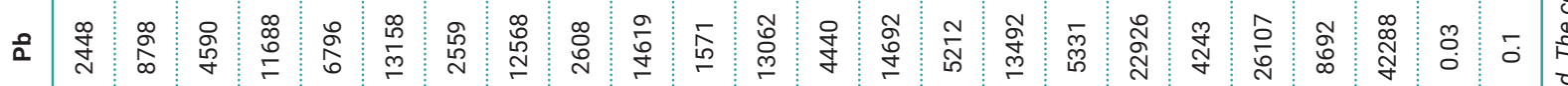

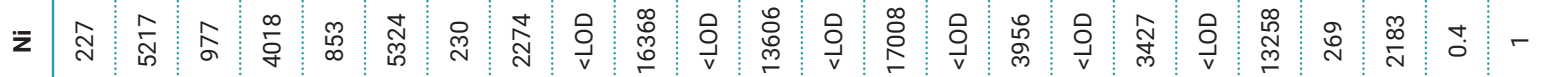

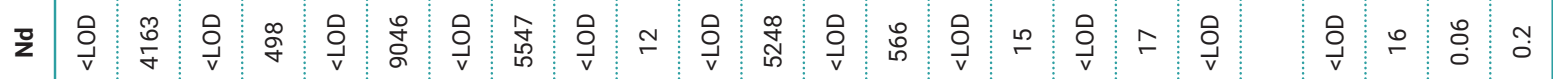

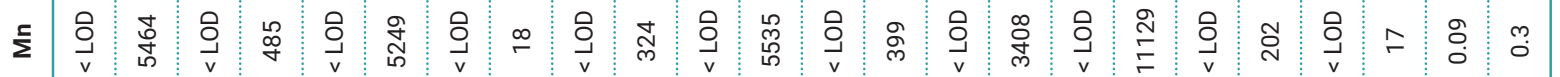

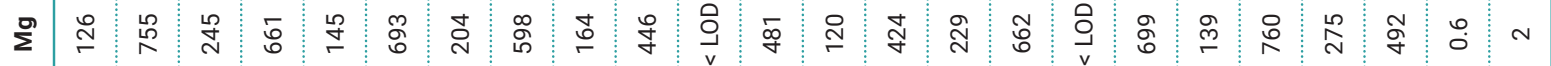
ᄂ

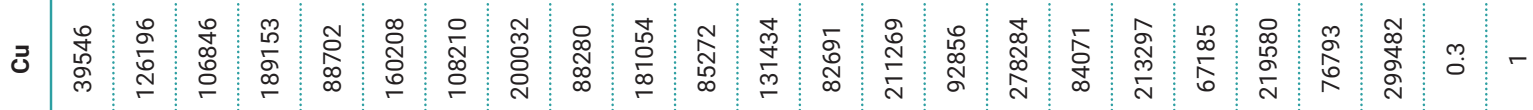
\begin{tabular}{c}
$c$ \\
\hline
\end{tabular} 8 o

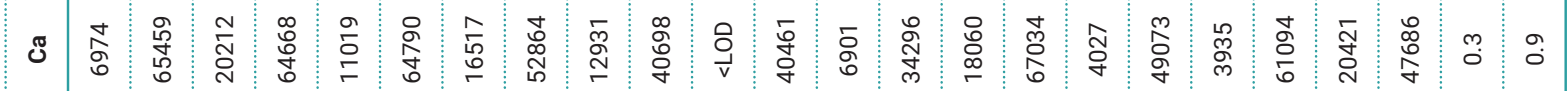

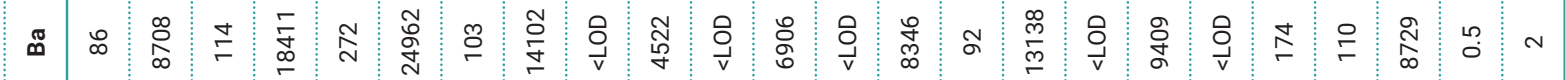
z

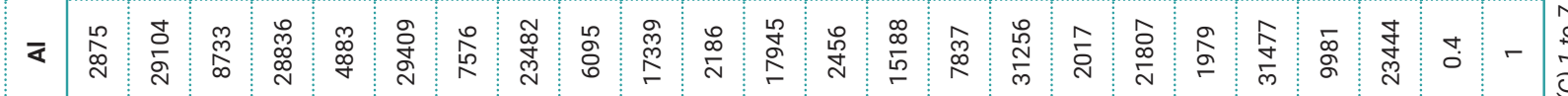

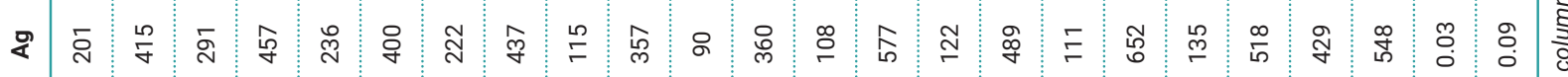

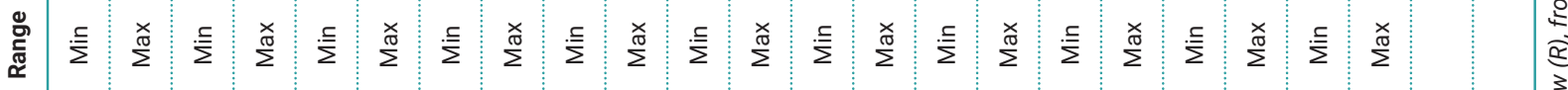

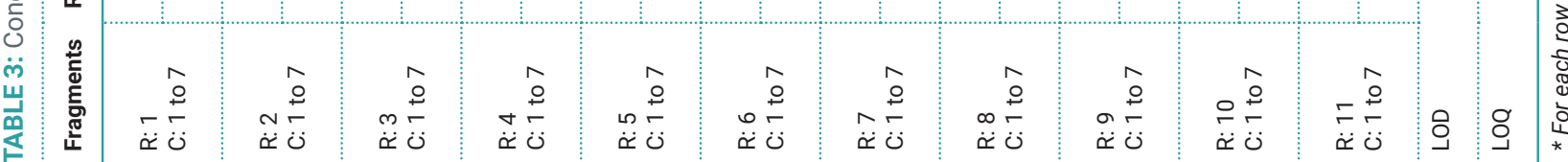



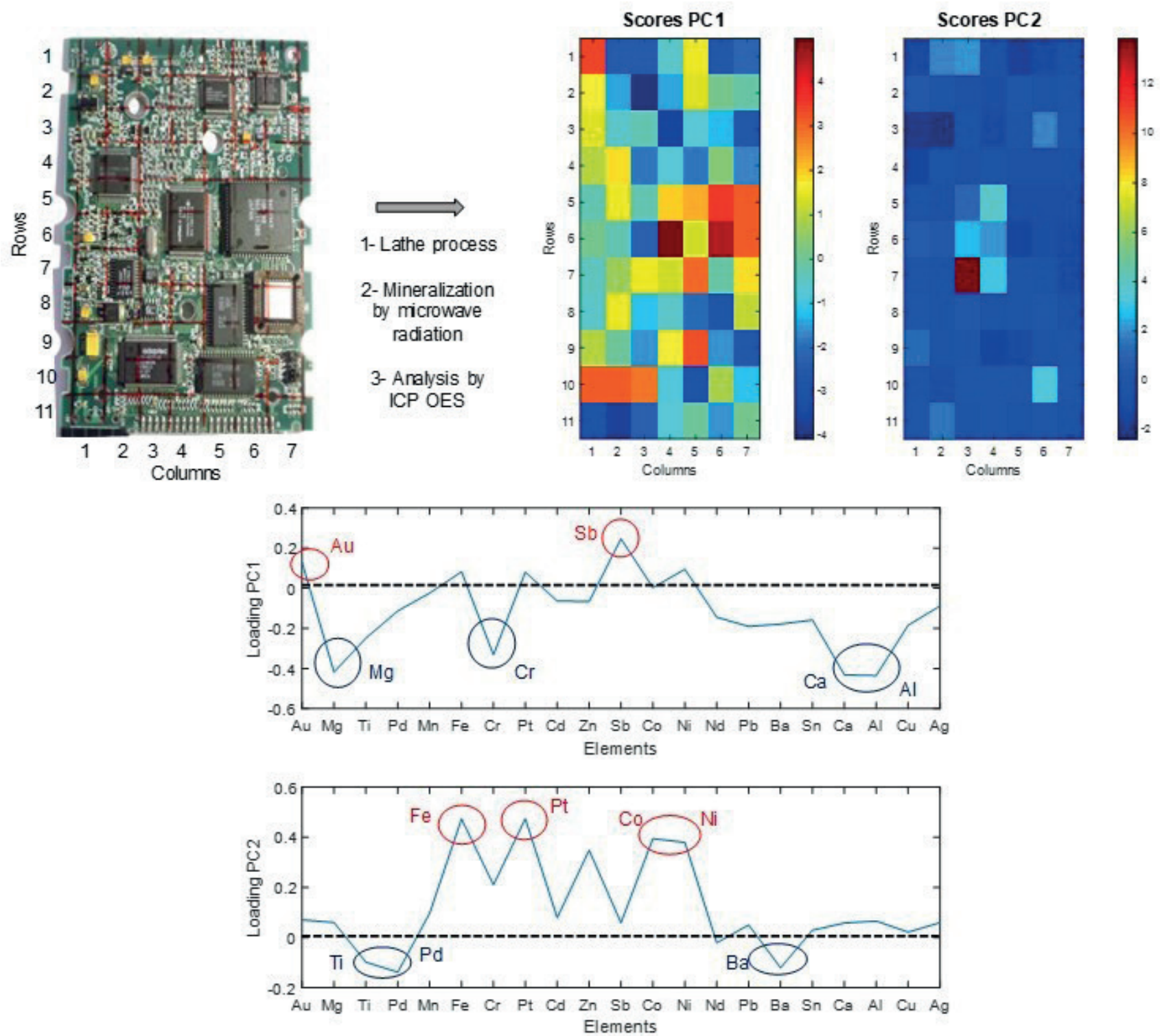

FIGURE 1: Scores map and loading plot of the PCB with decomposition in two principal components (PC1 and PC2).

and PC2. The scores represent the sub-samples and, the loadings the variables.

In this case, the red and blue colors are correlated with positive and negative loadings, respectively. According to PC1, the red spots (scores PC1) are more correlated with $\mathrm{Au}$ and $\mathrm{Sb}$ (loading PC1), and the blue spots with $\mathrm{Mg}, \mathrm{Cr}, \mathrm{Ca}$ and $\mathrm{Al}$. For PC2, the red spot (scores PC2) is more correlated with Fe, Pt, Co and Ni (loading PC2), and the blue spots with $\mathrm{Ti}, \mathrm{Pd}$ and $\mathrm{Ba}$.

Another way to visualize this data is with the correlation plot that is shown in Figure 2. This plot is based on Pearson correlation, that shows how close two variables are to obtaining a linear relationship. The correlation value $(R)$ range from -1 to 1 and this number refers: (1) correlations close to 1 , that means a positive correlation where the variables change in the same direction; (2) null correlation (close to 0 ), none relationship between variables; (3) correlations close to -1 , that means negative correlation where the variables change in an opposite way. The red spots have a pos- itive correlation (close to 1), while the blue spots negative correlation (see the color bar for better interpretation).

$\mathrm{Ca}, \mathrm{Al}$ and $\mathrm{Mg}$, for instance, have a correlation close to 1 (maximum), and these three elements are correlated with $\mathrm{Cr}$ in a range of 0.8 . Figure 3 shows the individual distribution on the PCB of these four elements using the concentrations acquired from ICP OES. The plots were made using the function "imagesc" from MATLAB. With Figure 3, it is possible to observe that $\mathrm{Ca}, \mathrm{Al}$ and $\mathrm{Mg}$ have the same profile, with high concentration on the same sub-samples (rows 1 and 2 with columns 2 and 3, for example). And low concentration (blue spots) for sub-samples on the rows 5 and 6 with columns 5,6 and 7 (also similar for $\mathrm{Cr}$ ). The correlation of these three elements with $\mathrm{Cr}$ is not so high because just in some fragments the profile of $\mathrm{Cr}$ is similar with $\mathrm{Ca}, \mathrm{Al}$ and $\mathrm{Mg}$ (row 1 with columns 2 and 3, for example). $\mathrm{Ca}, \mathrm{Al}$ and $\mathrm{Mg}$ are present in the glass fiber used on the PCB. This material is composed of $\mathrm{SiO}_{2}$ with the highest concentration, followed by $\mathrm{CaO}_{2}$ and $\mathrm{Al}_{2} \mathrm{O}_{3}$. $\mathrm{MgO}$ is also 


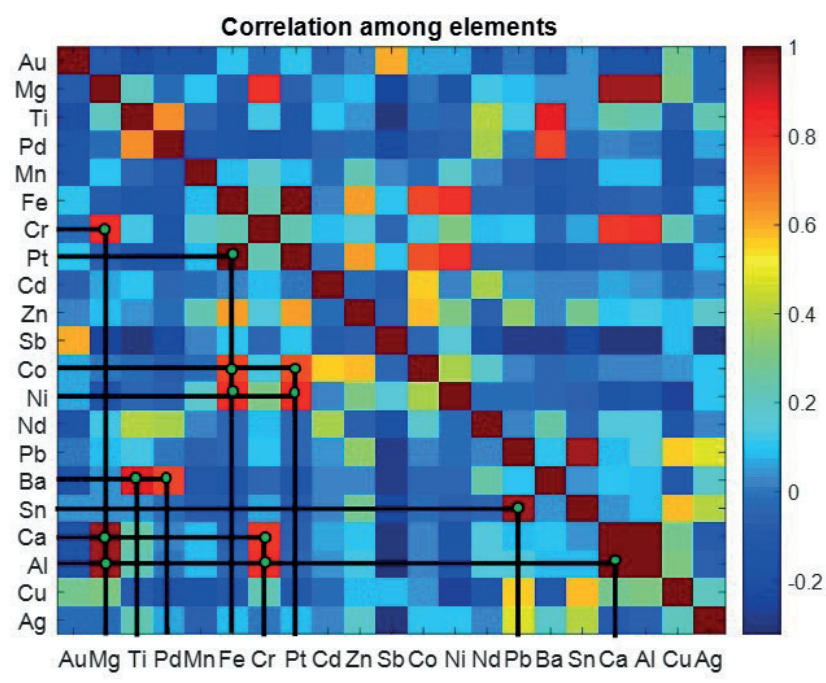

FIGURE 2: Correlation plot for all elements determined by ICP OES.

in the composition but with a lower concentration than $\mathrm{Ca}$ and $\mathrm{Al}$ (Sanapala, 2008), and this can be also observed in Figure 3 (see the color bar with the concentration values).

Other elements that have correlation close to 1 are Sn and $\mathrm{Pb}$ (Figure 2), which are on the solder material used to assemble the components on the PCB. The lead-based solders are banned in European Union, but in some regions are still used due to physic-chemical properties, high degree of "wetting" and the cost of Pb. Sn-Ag-Cu (Sanapala, 2008) and Ga-Sb-Zn (Dervisevic et al., 2013) alloys can be used as free-lead solder material, being the $\mathrm{Sn}-\mathrm{Ag}$-Cu alloy more used than Ga-Sb-Zn alloy. Figure 4 shows the individual distribution of $\mathrm{Pb}$ and $\mathrm{Sn}$ on the $\mathrm{PCB}$ and can be observed the same behavior for both elements, mainly concentrated on the row 11. Sn concentration is much higher than $\mathrm{Pb}$ concentration, which can be also found in anticorrosive coatings of other metals.

According to PC2 loading plot (Figure 1), Ba, Ti and Pd are correlated and observing Figure 2, this correlation is around 0.8 . On the other hand, it is more about $\mathrm{Ba} / \mathrm{Ti}$ and
$\mathrm{Ba} / \mathrm{Pd}$. The relationship between $\mathrm{Ba}$ and $\mathrm{Ti}$ may be due to the barium titanate present on the ceramic material as dielectric in capacitors. Figure 5 shows the individual distribution of $\mathrm{Ba}, \mathrm{Ti}$ and $\mathrm{Pd}$. It can be observed the similar profile between $\mathrm{Ba}$ and $\mathrm{Ti}$. But, for $\mathrm{Ba}$ and $\mathrm{Pd}$, it can be considered an indirect correlation, where on row 3 and columns 1, 2 and 4 , there are high concentration of $\mathrm{Ba}$ and $\mathrm{Pd}$. The platinum group elements are used as coatings in switches and sensors.

Elements as Pt, Fe, Co and $\mathrm{Ni}$ appear correlated in PC2 loading plot (Figure 1) with Zn being also in the same plot quadrant. The correlation plot (Figure 2) contain Pt with Fe in a correlation close to $1, \mathrm{Co} / \mathrm{Ni}$ with $\mathrm{Fe}$ and $\mathrm{Co} / \mathrm{Ni}$ with $\mathrm{Pt}$ in a correlation close to 0.8 , but for $\mathrm{Zn}$ the correlation decrease around 0.6. Figure 6 shows the individual distribution for these elements. They have a similar behavior, mainly on the row 7 and columns 3 and 4 . These elements can be found in some components on $\mathrm{PCB}$, Fe in magnetic components and $\mathrm{Ni}$ in conductive films in resistors, for example.

A last correlation in the PC1 loading plot (Figure 1) is for $\mathrm{Au}$ and $\mathrm{Sb}$ with a value around 0.6 (Figure 2, correlation plot). Figure 7 shows the individual distribution on the PCB. The profile is a little bit similar with high concentration on row 10 and column 3, for example. Gold is used as coating of connection pins of micro-chips and in integrated circuits. Antimony can be used in soldering, Cu plating or connect to it on the connecting pins, as a semiconductor dopant, in addition, as additive of flame retardant polymeric composites.

There are other elements in Figure 2, but with low correlations with each other. For example, $\mathrm{Cu}$ is the most abundant element on the PCB and, in Figure 2 appears with low correlation with other elements. $\mathrm{Cu}$ is used on printed circuit tracks and in the connecting pins, in addition, it is also used in some electronic components.

\section{CONCLUSIONS}

The possibility of sample preparation without gridding
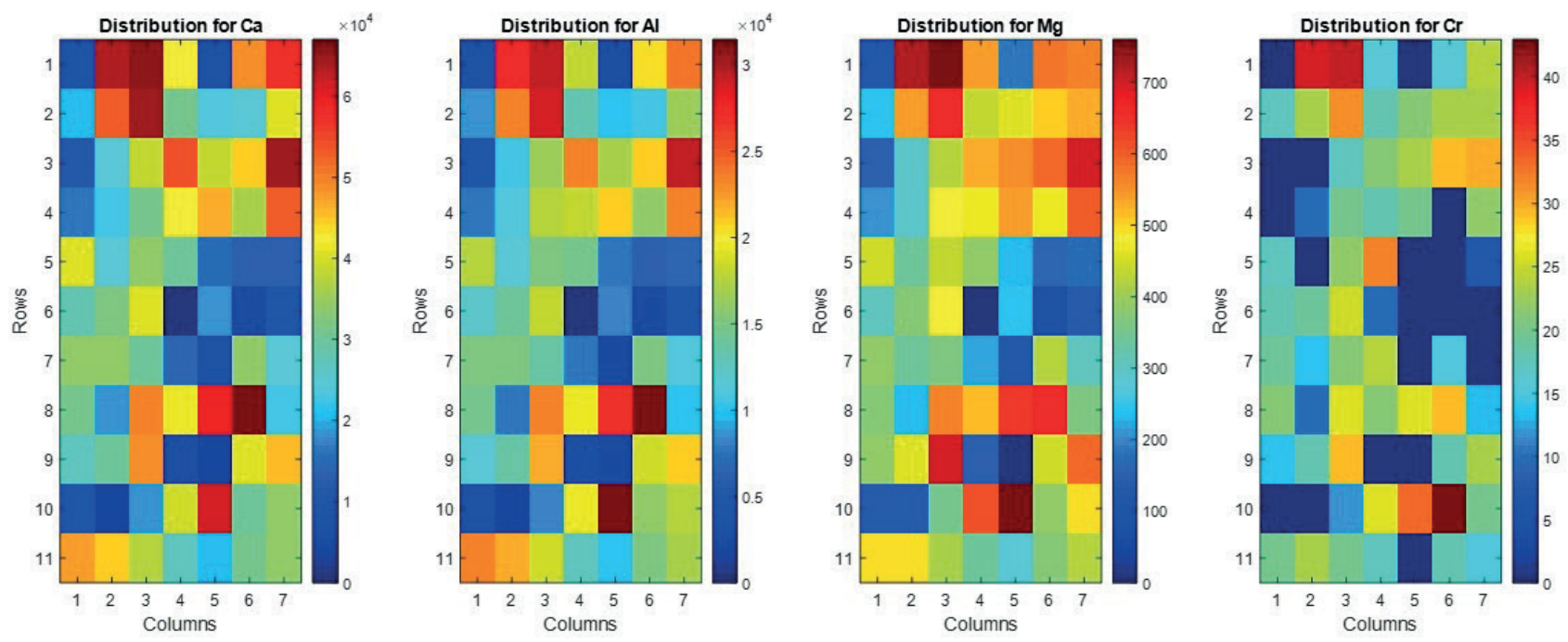

FIGURE 3: Distribution of $\mathrm{Ca}, \mathrm{Al}, \mathrm{Mg}$ and $\mathrm{Cr}$ on the PCB with individual concentration acquired by ICP OES. 

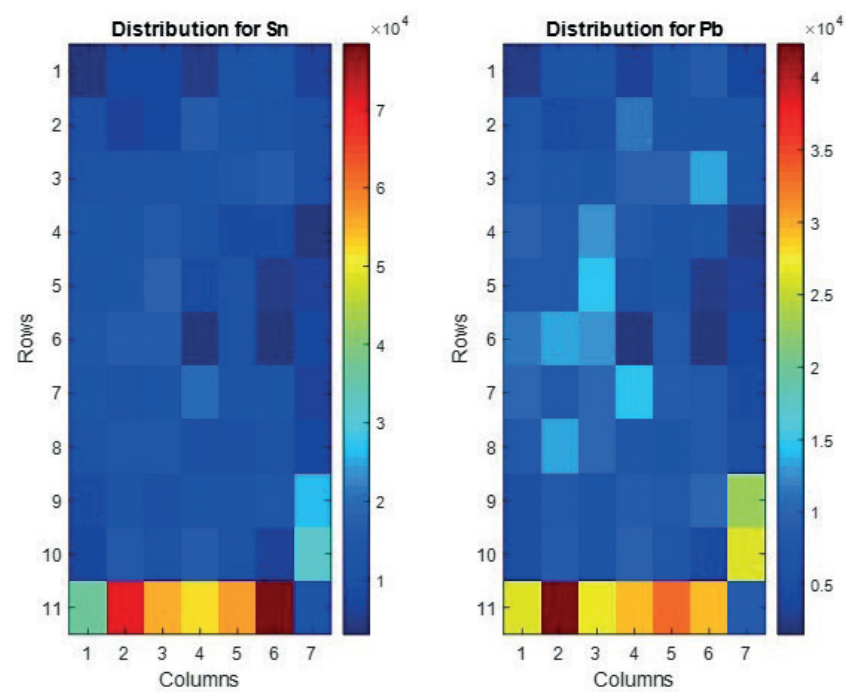

FIGURE 4: Distribution of $\mathrm{Sn}$ and $\mathrm{Pb}$ on the PCB with individual concentration acquired by ICP OES.
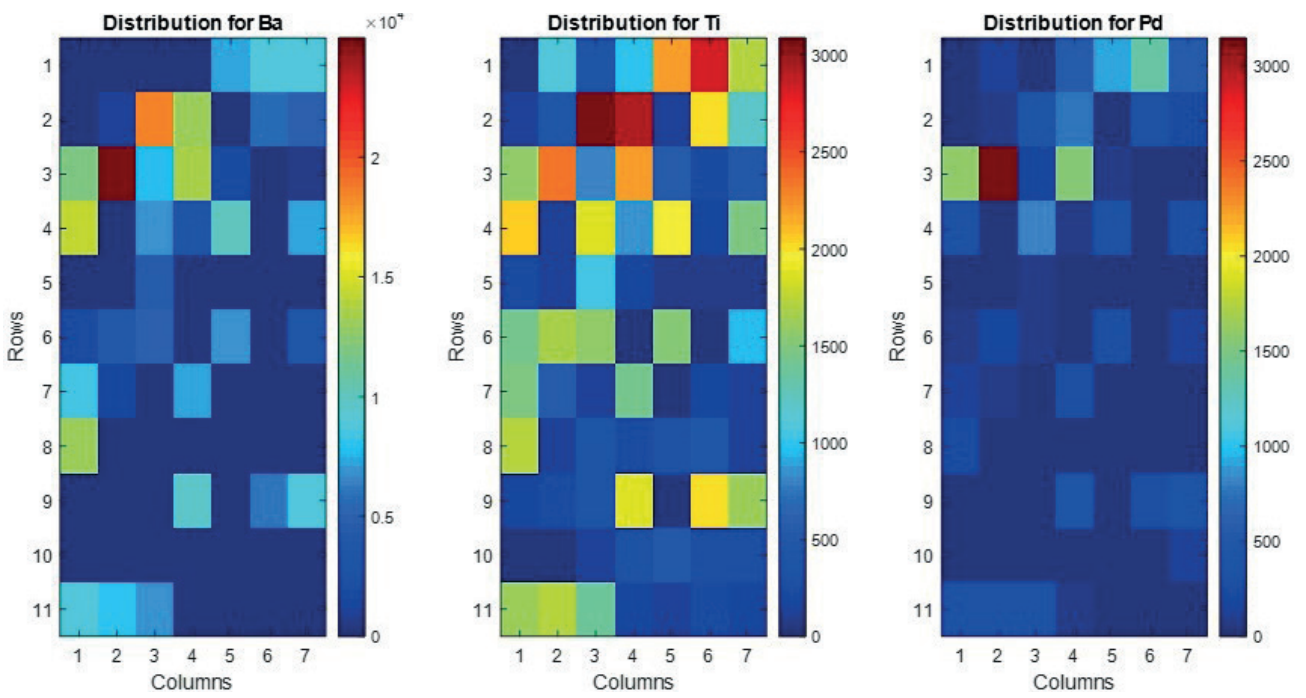

FIGURE 5: Distribution of Ba, Ti and Pd on the PCB with individual concentration acquired by ICP OES.
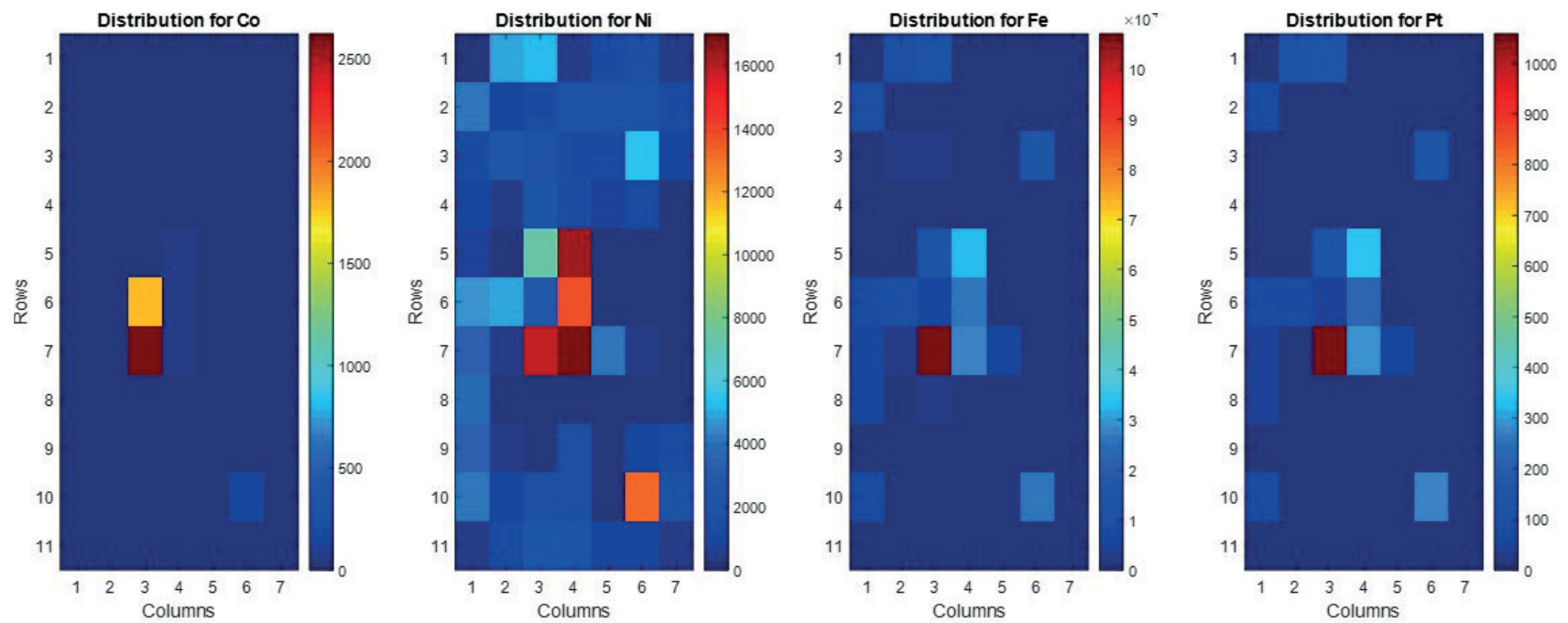

FIGURE 6: Distribution of $\mathrm{Co}, \mathrm{Ni}, \mathrm{Fe}$ and Pt on the PCB with individual concentration acquired by ICP OES. 

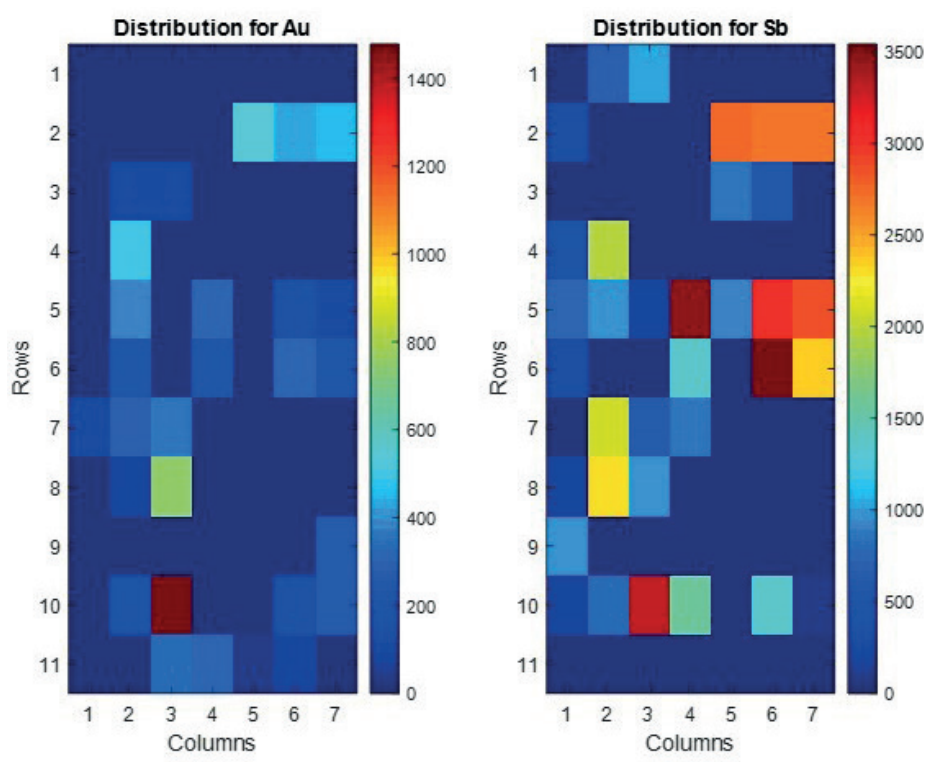

FIGURE 7: Distribution of $\mathrm{Au}$ and $\mathrm{Sb}$ on the PCB with individual concentration acquired by ICP OE.

process may avoid material loss, improving the detectability, and figures of merit of the proposed method. In addition, the use of several images contributed to better interpretation of ICP OES results. Each figure complements the other, while scores map and loading plot show the main correlation among elements, correlation plot presents how closely correlated these elements are and, individual distribution shows how is this correlation around the PCB components. Therefore, it is a promising way to visualize and interpret the data, contributing to urban mining and recycling.

\section{ACKNOWLEDGMENTS}

This study was supported by the São Paulo Research Foundation (FAPESP, grants 2012/01769-3, 2012/50827$6,2014 / 22408-4,2016 / 01513-0,2016 / 17221-8$ and 2018/17753-5) and Conselho Nacional de Desenvolvimento Científico e Tecnológico (CNPq, 401074/2014-5, $305637 / 2015-0$ and $141311 / 2017-7)$. This study was financed in part by the Coordenação de Aperfeiçoamento de PessoaldeNívelSuperior-Brasil(CAPES)-FinanceCode001.

\section{REFERENCES}

Andrade, D. F., Romanelli, J. P., \& Pereira-Filho, E. R. (2019a). Past and emerging topics related to electronic waste management: top countries, trends, and perspectives. Environmental Science and Pollution Research, 26, 17135-17151. https://doi.org/10.1007/ s11356-019-05089-y.

Andrade, D. F., Machado, R. C., Bacchi, M. A., \& Pereira-Filho, E. R. (2019b). Proposition of electronic waste as a reference material - Part 1: sample preparation, characterization and chemometric evaluation. Journal of Analytical Atomic Spectrometry, 34, 23942401. DOI: $10.1039 /$ C9JA00283A.

Andrade, D. F., Machado, R. C., \& Pereira-Filho, E. R. (2019c). Proposition of electronic waste as a reference material - part 2: homogeneity, stability, characterization, and uncertainties. Journal of Analytical Atomic Spectrometry, 34, 2402-2410. DOI: 10.1039/c9ja00284g.

Baldé, C. P., Forti, V., Gray, V., Kuehr, R., \& Stegmann, P. (2017). The Global E-waste Monitor 2017. United Nations University (UNU), International Telecommunication Union (ITU) \& International Solid Waste Association (ISWA), Bonn/Geneva/Vienna.
Bookhagen, B., Obermaier, W., Opper, C., Koeberl, C., Hofmann, T., Prohaska, T., \& Irrgeher, J. (2018). Development of a versatile analytical protocol for the comprehensive determination of the elemental composition of smartphone compartments on the example of printed circuit boards. Analytical Methods, 10, 3864-3871. DOI: 10.1039/c8ay01192c.

Carvalho, R. R. V., Coelho, J. A. O., Santos, J. M., Aquino, F. W. B., Carneiro, R. L., \& Pereira-Filho, E. R. (2015). Laser-induced breakdown spectroscopy (LIBS) combined with hyperspectral imaging for the evaluation of printed circuit board composition. Talanta, 134, 278283. https://doi.org/10.1016/j.talanta.2014.11.019.

Castro, J. P., \& Pereira-Filho, E. R. (2018). Spectroanalytical method for evaluating the technological elements composition of magnets from computer hard disks. Talanta, 189, 205-210. https://doi. org/10.1016/j.talanta.2018.06.062.

Cayumil, R., Ikram-Ul-Haq, M., Khanna, R., Saini, R., Mukherjee, P. S., Mishra, B. K., \& Sahajwalla, V. (2018). High temperature investigations on optimising the recovery of copper from waste printed circuit boards. Waste Management, 73, 556-565. http://dx.doi. org/10.1016/j.wasman.2017.01.001

Costa, V. C., Castro, J. P., Andrade, D. F., Babos, D. V., Garcia, J. A., Sperança, M. A., Catelani, T. A., \& Pereira-Filho, E. R. (2018). Laser-induced breakdown spectroscopy (LIBS) applications in the chemical analysis of waste electrical and electronic equipment (WEEE). Trends in Analytical Chemistry, 108, 65-73. https://doi. org/10.1016/j.trac.2018.08.003.

Cucchiella, F., D'Adamo, I., Koh, S. C. L., \& Rosa, P. (2015). Recycling of WEEEs: An economic assessment of present and future e-waste streams. Renewable and Sustainable Energy Reviews, 51, 263272. http://dx.doi.org/10.1016/j.rser.2015.06.010.

Cui, J., \& Zhang, L. (2008). Metallurgical recovery of metals from electronic waste: A review. Journal of Hazardous Materials, 158, 228256. Doi: 10.1016/j.jhazmat.2008.02.001.

Dervisevic, I., Minic, D., Kamberovic, Z., Cosovic, V., \& Ristic, M. (2013). Characterization of PCBs from computers and mobile phones, and the proposal of newly developed materials for substitution of gold, lead and arsenic. Environmental Science and Pollution Research, 20, 4278-4292. DOI 10.1007/s11356-012-1448-1.

El-Nasr, R. S., Abdelbasir, S. M., Kamel, A. H., \& Hassan, S. S. M. (2020). Environmentally friendly synthesis of copper nanoparticles from waste printed circuit boards. Separation and Purification Technology, 230, 115860. https://doi.org/10.1016/j.seppur.2019.115860.

Huang, K., Guo, J., \& Xu, Z. (2009). Recycling of waste printed circuit boards: A review of current technologies and treatment status in China. Journal of Hazardous Materials, 164, 399-498. Doi: 10.1016/j.jhazmat.2008.08.051. 
Mesquita, R. A., Silva, R. A. F., \& Majuste, D. (2018). Chemical mapping and analysis of electronic componentsfrom waste PCB with focus on metal recovery. Process Safety and Environmental Protection, 120, 107-117. https://doi.org/10.1016/j.psep.2018.09.002.

Moosakazemi, F., Ghassa, S., Soltani, F., \& Mohammadi, M. R. T. (2020). Regeneration of $\mathrm{Sn}-\mathrm{Pb}$ solder from waste printed circuit boards: A hydrometallurgical approach to treating waste with waste. Jounal of Hazardous Materials, 385, 121589. https://doi.org/10.1016/j. jhazmat.2019.121589.

Park, Y. J., \& Fray, D. J. (2009). Recovery of high purity precious metals from printed circuit boards. Journal of Hazardous Materials, 164, 1152-1158. Doi: 10.1016/j.jhazmat.2008.09.043.

Rao, M. D., Singh, K. K., Morrison, C. A., \& Love, J. B. (2020). Challenges and opportunities in the recovery of gold from electronic waste. Royal Society of Chemistry Advances, 10, 4300-4309. DOI: $10.1039 / \mathrm{c} 9 \mathrm{ra07607g}$

Sanapala, R. (2008). Characterization of FR-4 Printed Circuit Board Laminates Before and After Exposure to Lead-free Soldering Conditions. Thesis submitted to the Faculty of the Graduate School of the University of Maryland.

Santos, M. C., Dai, C., \& Pereira, F. M. V. (2018). Chemical element profiles in commercial woven fabric combining laser-induced breakdown spectroscopy and chemometrics. Journal of Applied Spectroscopy, 85, 543-551. DOI 10.1007/s10812-018-0685-6.
Silvas, F. P. C., Correa, M. M. J., Caldas, M. P. K., De Moraes, V. T., Espinosa, D. C. R., \& Tenório, J. A. S. (2015). Printed circuit board recycling: Physical processing and copper extraction by selective leaching. Waste Management, 46, 503-510. http://dx.doi. org/10.1016/j.wasman.2015.08.030.

Sperança, M. A., Aquino, F. W. B., Fernandes, M. A., Lopez-Castillo, A., Carneiro, R. L., \& Pereira-Filho, E. R. (2017). Application of Laser-induced breakdown spectroscopy and hyperspectral images for direct evaluation of chemical elemental profiles of coprolites. Geostandards and Geoanalytical Research, 41, 273-282. https://doi. org/10.1111/ggr.12155.

Tanvar, H., Barnwal, A., \& Dhawan, N. (2020). Characterization and evaluation of discarded hard disc drives for recovery of copper and rare earth values. Journal of Cleaner Production, 249, 119377. https://doi.org/10.1016/j.jclepro.2019.119377.

Yamane, L. H., De Moraes, V. T., Espinosa, D. C. R., \& Tenório, J. A. S. (2011). Recycling of WEEE: Characterization of spent printed circuit boards from mobile phones and computers. Waste Management, 31, 2553-2558. Doi: 10.1016/j.wasman.2011.07.006.

Zhang, S., Ding, Y., Liu, B., Chang, C-C. (2017). Supply and demand of some critical metals and present status of their recycling in WEEE, Waste Management, 65, 113-127. http://dx.doi.org/10.1016/j.wasman.2017.04.003. 